\title{
28 Social protection for women informal workers
}

\author{
Perspectives from Latin America
}

\author{
Silke Staab
}

For the majority of working women and men, the promise of universal social protection remains unfulfilled. Labor market informality is a key driver of this exclusion. Gender biases and inequalities - in markets, households, laws and policies - exacerbate this exclusion for women, including women in informal employment - by systematically devaluing women's work.

The widespread legal exclusion of domestic workers - one of the most feminized categories among the informally employed - from formal social protection schemes, for example, reflects gendered conceptions of domestic work not being "real" work and hence unworthy of the legal and social protections offered to other kinds of wage labor. Similar conceptions about what kinds of work are appropriate for women and men and the value that is attached to them also shape patterns of occupational segregation within the informal economy. Women are concentrated at the bottom of the famous WIEGO (Women in Informal Employment: Globalizing and Organizing) earnings pyramid (as contributing family workers and home-based industrial out-workers) (see Chapter 6 in this volume), while men are more likely to dominate among informal employers or informal wage workers (Chen 2009).

Gender norms and power relations also shape the division of labor in families and communities. The disproportionate responsibility placed on women for doing household-related chores and looking after children and other dependents means that women interrupt employment more frequently than men and contributes to their concentration in jobs with limited access to social protection. Women in informal employment often cite family responsibilities as one of the reasons for being in less protected work - because it offers greater "flexibility" though this flexibility often comes at the price of lower productivity, higher stress levels and potential risks to the well-being of both women and the dependents they look after while also trying to get their work done.

As a result, classical social security schemes - designed for uninterrupted work trajectories in formal employment that enables regular contributions to social insurance - have not worked well for women (in general), informal workers (in general) and women in informal employment (in particular). In Latin America, only 4 out of 10 ten older adults have a contributory pension, i.e., one that is linked to previous payroll contributions (Bosch, Melguizo and Pagés 


\section{Silke Staab}

2013). In most countries with available data, women are overrepresented among those excluded from social protection; and in some, such as the Dominican Republic and El Salvador, women's old-age coverage is less than half of the already low coverage of men (UN Women 2015).

Does this mean that de-linking social protection from employment-based contributory systems is the solution? Developments in Latin American social protection schemes over the past two decades show that the answer to this question depends to a large degree on what "de-linking" is understood to mean.

\section{Isolated transfers versus integrated social protection systems}

If de-linking means the promotion of non-contributory programs (i.e., social assistance) as an alternative to employment-based, contributory social security schemes - which is what the 2019 World Development Report seemed to suggest (World Bank 2018) ${ }^{1}$ - then the answer to the question above is clearly no. This would not only risk eroding benefits that many workers currently rely on, but also let employers - who are meant to pay their fair share into social security systems - off the hook. The answer is also no if de-linking takes the form of fairly isolated and narrowly targeted cash transfers based on means-testing and attached to conditionalities for their recipients. The risk that women in informal employment might fall through the cracks in this case is high because they may not be considered "poor enough" to qualify. They may also be burdened with fulfilling the conditions attached to the transfer, such as attending parenting workshops or taking children to check-ups at health care centers that may be difficult to reach, run on schedules that are out of sync with their working hours, or involve extensive waiting times. These are the main criticisms leveled at conditional cash transfer programs by gender equality advocates since the early 2000s when these programs started spreading, first, across Latin America and from there to virtually every other region of the world (e.g., Molyneux 2006; Cookson 2018).

But much has happened in Latin America (and elsewhere) since these transfers were first introduced - including efforts to build integrated social protection systems that combine and integrate contributory (i.e., linked) and noncontributory (i.e., de-linked) elements to enhance the income security of all independent of whether they work in formal or informal employment and indeed of whether they work for pay at all.

These efforts have been insufficient and uneven across countries and in many cases started stalling against the economic downturn that affected the region from 2010 onwards (UN Women 2017). However, in many countries in the region, the aspiration and associated policies to move toward universal social protection systems have benefited women, including women in informal employment. Two main strategies come to the fore.

On the one hand, there have been efforts to bring informal workers under the coverage of existing contributory schemes. The case of Uruguay is illustrative. Here, the rates of domestic workers who are covered for health, pensions, unemployment and maternity leave - through mandatory payroll contributions by their 
employers - rose from 27 to 67 percent between 2004 and 2014 (Meier 2010; Cortés 2016). This has been achieved through a combination of legal reforms accompanied by awareness-raising, incentives and enforcement in an exceptionally enabling economic and political environment - including the creation of a tripartite wage council in 2008 that enables the domestic workers union to collectively bargain with employer representatives. The SIMPLES scheme in Brazil is another positive story where incentives for informal enterprises to formalize their activities have not only linked those enterprises to the tax system, but also brought their workers under social security coverage. But such success stories are not widespread.

Overall, the incorporation of informal workers into contributory schemes seems to have worked better in countries that already had fairly high levels of social security coverage (Costa Rica and Uruguay, and to a lesser extent Argentina, Brazil and Chile). In countries with low overall contributory social security coverage, such as Mexico and Paraguay, for example, the rates of domestic workers who contribute have risen very slowly and remained under 3 percent in 2014. It has also been relatively more effective for informal wage workers, such as temporary agricultural workers, domestic workers or workers in informal enterprises where employers can be obliged or incentivized to contribute their share than for the self-employed - though a segment of the self-employed, i.e., those who have more regular and higher average earnings, may be able to afford to make their own contribution to social security.

Home-based workers, street vendors and waste pickers are unlikely to be part of this group. These workers have likely never been linked to employment-based social security systems and are unlikely to be linked by way of regular contributions, because their own earnings are too low and too intermittent and because in many cases there is no employer who could be obliged to pay their share.

Efforts to expand access to social protection that is more independent from labor market trajectories and contribution histories are hence important, particularly for informal workers at the bottom of the informal employment earnings pyramid which is where women are overrepresented. In most Latin American countries, the percentage of women who are able to fund their old age with a contributory pension is substantially lower than that of men. In this context, the expansion of non-contributory social pension, financed through general taxation, not only can boost overall coverage but also reduce the gender gap in access to pensions.

Over the past two decades, at least 15 countries in the region have introduced new non-contributory pension programs or expanded existing ones to reach a wider population. Consider Bolivia and Ecuador, two countries where overall coverage was very low in the mid-1990s. In 1995, when both countries relied largely on contributory pension systems, 35 and 22 percent of older people respectively had access to a pension, with coverage being much lower among women than among men. By 2016, the percentage of older people, women and men, with access to a pension had gone up to 97 and 59 percent respectively, while gender gaps had practically disappeared (see Figure 28.1). 


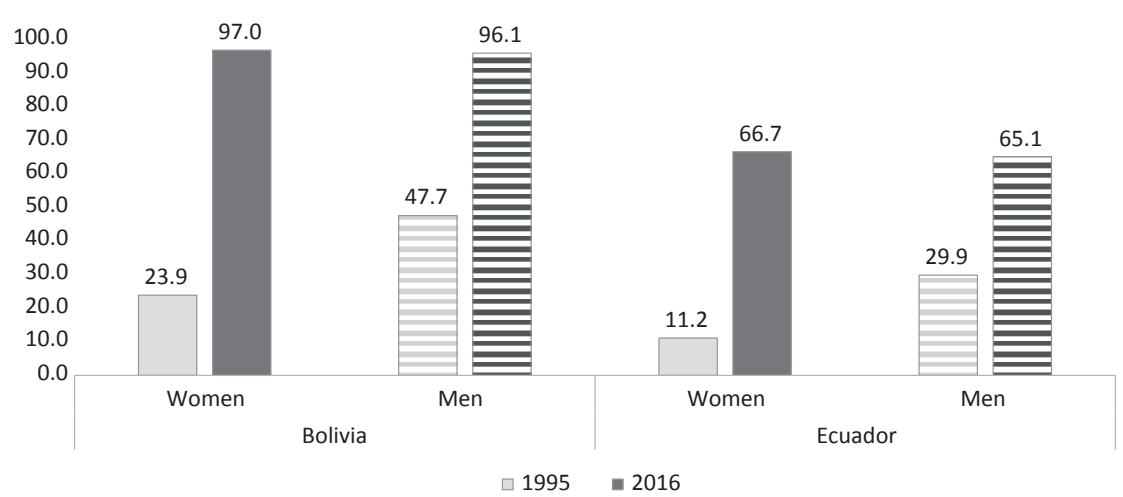

Figure 28.1 Bolivia and Ecuador: pension coverage (contributory and non-contributory) by sex, 1995 and 2016.

Source: Author's calculations based on data from Inter-American Development Bank's Labour Markets and Social Security Information System (The SIMS), https://mydata.iadb.org/Labor/ Database-of-Labor-Markets-and-Social-Security-Info/v2c9-36h7/data (accessed 11 March 2019).

In several countries in the region, including Bolivia, Ecuador and Mexico, non-contributory benefits now reach more people than contributory pensions (IADB 2019). In others, such as Uruguay, where labor markets are more formalized, non-contributory pensions play a more residual, but nevertheless important role in complementing contributory schemes to achieve universal coverage.

The main take-away from this is that solutions need to be tailored to the specific needs and capacities of different groups of informal workers. They also need to take account of existing pension systems and identify the most promising approaches for closing the remaining gaps. What works for some will not necessarily work for others. Stitching these solutions together into a coherent whole that moves toward universal coverage and gradually overcomes the stark inequalities in access to and adequacy of social protection both among different groups of workers and among women and men, remains one of the main challenges for Latin America (Arza and Franzoni 2018).

\section{From de-linking to rethinking social protection}

Social protection systems that work for women in informal employment do not only require linking or de-linking. They require a more radical rethinking. One of the main aims of social protection is to guarantee basic income security to all, whatever their employment trajectories or capacity to contribute to social insurance schemes. They should have a pension when they can no longer work; they should have health care when they get sick; and they should receive maternity benefits to be able to stop working before and after childbirth. What is not often explicitly recognized in mainstream social protection frameworks 
is that the income security of women is significantly compromised by their unpaid care responsibilities. Labor market earnings are their main source of income and they get less of those because they do not have access to affordable and reliable services that would free up the time they spend on caring for aging parents, sick relatives or small children for productive activities (UN Women 2015; Alfers 2016).

Among developing regions, Latin America has been at the forefront of debates around unpaid care and domestic chores. Alongside efforts to expand social protection, the coverage of care services for children of pre-school age has increased significantly between 2000 and 2010. In Ecuador, for example, the enrollment of children aged 0-3 years grew from less than 5 percent to over 20 percent. In Brazil and Chile, which had enrollment rates of 12 percent and 11 percent respectively in 2002, this had increased to 21 percent and 26 percent by 2010 (UN Women 2017). Much of this expansion was state-led, that is, accompanied by significant fiscal investments, and important (albeit insufficient) efforts to improve service quality as well as the working conditions of staff. Nevertheless, significant gaps in coverage remain and services are not necessarily aligned with the needs of working parents. Most services are offered on a half-day basis, for example.

Some informal worker organizations have taken childcare matters into their own hands, advocating for or offering services that are better attuned to the needs of their constituency (Moussié 2017). This is important and WIEGO has rightly recognized childcare as a strategic area of engagement, one that is gaining momentum and where it can contribute to make a difference by highlighting the specific needs of women in informal employment as both providers and recipients of paid childcare services.

\section{Implications for research and policy advocacy}

The two points above raise a number of concerns and challenges for future research and advocacy on social protection for women in informal employment. They highlight the need for context- and status-specific research and analysis of social protection systems. What works for which groups of workers? What types of informal workers can be meaningfully linked to contributory social protection schemes? What might be gained and lost for informal workers by de-linking social protection from labor force participation in different contexts?

Further research is also needed to deepen the understanding of the relation between informal employment, care/reproductive work and public policy in the lives of women in informal employment. How does one type of work affect the other? How well do social protection (and other policies, such as urban planning) respond to the multiple roles and struggles of women in informal employment? What are potential functional equivalents to classical social protection schemes for women in informal employment?

In terms of social protection advocacy for informal workers, one of the key challenges is to adopt a systemic perspective without losing the focus on 


\section{Silke Staab}

informal workers. The most effective and sustainable policy solutions may not necessarily be the ones that are targeted specifically at informal workers, but those that are aimed at creating universal systems with a broad-based constituency who can be brought into sustaining services and benefits financially (through progressive taxation or cross-subsidies) and politically (through mobilization and claims-making). The policy debates in this area are not always or exclusively about informal workers, but about recognition and redistribution more broadly and the creation of alliances for universal social protection systems that provide workable solutions for all those who are currently excluded.

\section{Note}

1 For a critical reading of the WDR's social protection discussion, see Alfers (2018) and Staab (2018). 